\title{
COMPACTAÇÃO E FERTILIDADE DO SOLO APÓS COLHEITA DO EUCALIPTO UTILIZANDO FELLER BUNCHER E SKIDDER
}

\author{
Ana Lúcia Piedade Sodero Martins Pincelli ${ }^{1 *}$, Fernando Seixas ${ }^{1}$, Ricardo Nunes ${ }^{1}$ \\ *Autor para correspondência: analucia.sodero@hotmail.com
}

\begin{abstract}
RESUMO: Analisou-se, nesse estudo, o impacto do tráfego do "Feller Buncher" e "Skidder" nas operações de colheita em áreas de eucalipto no município de Mogi Guaçu, quanto à compactação e fertilização em faixa de solo próxima ao carreador, durante o ciclo de crescimento da floresta. Observou-se que houve um incremento na compactação causada pelo trânsito de máquinas, na camada superficial do solo $(0-10 \mathrm{~cm})$, na área recém-colhida de eucalipto. Os solos das áreas de estudo com eucalipto de 1,4 e 6,05 anos de idade apresentaram boas condições de fertilidade, destacando-se a área com eucalipto mais velho, cuja decomposição dos resíduos florestais contribuiu, possivelmente, para tal fertilidade.
\end{abstract}

Palavras-chave: resistência à penetração, densidade do solo, resíduos florestais.

\section{COMPACTION AND SOIL FERTILITY AFTER EUCALYPTUS HARVESTING USING FELLER BUNCHER AND SKIDDER}

\begin{abstract}
This study analyzed, the impact of Feller Buncher and Skidder traffic in harvesting areas of eucalyptus in Mogi Guaçu, considering the compaction and fertilization effects in the range of soil next to the carrier during the cycle of forest growth. An increase in soil compaction, caused by machinery traffic in topsoil $(0-10 \mathrm{~cm})$, was observed in the area recently harvested. The soils of the study areas, with eucalyptus 1.4 and 6.0 years old, showed good fertility conditions, especially the older area, where decomposition of forest residues possibly contributed to such fertility.
\end{abstract}

Keywords: penetration resistance, bulk density, forest residues.

\section{INTRODUÇÃO}

A colheita mecanizada de florestas envolvendo o tráfego de veículos pesados implica em alguns impactos no ecossistema, podendo resultar em danos às árvores remanescentes, em caso de desbastes, prejuízos à capacidade de rebrota das cepas, influência na qualidade dos recursos hídricos e na compactação do solo.

$\mathrm{O}$ impacto mais significativo nos atributos físicos do solo sob florestas está relacionado ao tráfego de veículos durante as operações, principalmente de colheita e extração da madeira. Essas atividades alteram a estrutura e os atributos físico-hídricos do solo, dificultando o crescimento e a distribuição das raízes no solo e, consequentemente, o desenvolvimento das florestas (DIAS JUNIOR et al., 2005).

Durante a retirada de madeira de povoamentos florestais, as máquinas podem trafegar numa mesma linha várias vezes, causando a compactação do solo e facilitando o processo erosivo, em decorrência do maior escorrimento superficial, que gera perdas de solo e nutrientes (CZYZ, 2004). O grau de compactação, além do número de passadas, pode também ser influenciado pelo peso de madeira transportada, com a deformação, ocorrendo quando as pressões aplicadas ao solo excederem sua capacidade de suporte de carga (DIAS JUNIOR, 2000).

No caso de reflorestamentos, o módulo de colheita de madeira utilizado condiciona o porcentual da área que será atingida pelo deslocamento das máquinas. Segundo Fenner (2002), a utilização de "Feller Buncher" e "Skidder" implica que, praticamente, toda a área sofrerá tráfego pelo menos uma vez.

A compactação causa mudanças desfavoráveis na densidade, porosidade, permeabilidade e resistência do solo à penetração (ISHAQ et al., 2001). A resistência à penetração aumenta com a compactação do solo, sendo restritiva ao crescimento radicular acima de valores, que variam de 1,5 a 3,0 MPa, conforme Grant e Lafond (1993), e de 2,0 a 4,0 MPa, segundo Oussible et al. (1992).

Lima et al. (2001) avaliaram o comportamento da resistência do solo à penetração em trilhas entre linhas de plantio de eucalipto. O sistema de colheita consistiu de um "Feller Buncher" com pneus diagonais e de um "Skidder" com pneus de baixa pressão. Segundo esses autores, a

1 Universidade de São Paulo - São Paulo, São Paulo, Brasil

Cerne, Lavras, v. 20, n. 2, p. 191-198, abr./jun. 2014 
resistência do solo à penetração variou após o tráfego dos equipamentos, sendo que a variação mais acentuada ocorreu na profundidade de $0-10 \mathrm{~cm}$, sendo crescente com o aumento da profundidade.

Por outro lado, o conhecimento da alocação de biomassa florestal é importante para o entendimento dos processos de ciclagem de nutrientes e é essencial para definições das estratégias de manejo a serem adotadas, como a aplicação de fertilizantes e a intervenção por meio de desbaste. Conforme estudos de Gonçalves et al. (1997), a taxa anual de deposição de serrapilheira em um povoamento de E. grandis (7 aos 8 anos) foi de 7,8 tha ${ }^{-1}$ ano $^{-1}$ ( $60 \%$ de folhas e $40 \%$ de galhos). Neste trabalho, após 6 meses do corte raso da floresta, a quantidade de serrapilheira acumulada sobre o solo reduziu de 24 para 16 t ha ${ }^{-1}$, ou seja, uma taxa de decomposição de $55 \%$ ao ano.

Diante do exposto, neste trabalho, objetivouse avaliar o impacto do tráfego do "Feller Buncher" e "Skidder" nas operações de colheita em áreas de eucalipto, quanto à fertilização e compactação em faixa de solo próxima ao carreador, durante o ciclo de crescimento da floresta.

\section{MATERIAL E MÉTODOS}

\subsection{Local}

Este estudo foi realizado em povoamentos de Eucalyptus spp., com espaçamento de $3 \times 2 \mathrm{~m}$, pertencentes a uma empresa do setor de papel e celulose do Estado de São Paulo. Foram selecionadas três áreas localizadas no município de Mogi Guaçu (S 22० 22' $15^{\prime}$ 'e W 46 56' 38”), com solos classificados como Argissolo VermelhoAmarelo (PVA) e de relevo plano a suave-ondulado. O tipo climático é o Cwa (temperado chuvoso mesotérmico), segundo a classificação de Koppen, com uma precipitação média anual de $1350 \mathrm{~mm}$, temperatura máxima média de $29,74{ }^{\circ} \mathrm{C}$ e a temperatura mínima média de $14,54{ }^{\circ} \mathrm{C}$.

\subsection{Descrição das máquinas}

O módulo utilizado para corte e extração de madeira incluíram, respectivamente, um "Feller Buncher" da marca Tigercat, modelo $860 \mathrm{C}$, potência nominal de $300 \mathrm{hp}(224 \mathrm{~kW})$, massa de $27.330 \mathrm{~kg}$, pressão aplicada sobre o solo de $0,07 \mathrm{MPa}$, equipado com esteiras e grua com alcance de $8,46 \mathrm{~m}$, e um "Skidder" da marca Tigercart, modelo 635D, potência nominal de $260 \mathrm{hp}(194 \mathrm{~kW})$, massa de $21.430 \mathrm{~kg}$, pressão aplicada sobre o solo, quando carregado com $9.300 \mathrm{~kg}$, de 0,03 MPa (pneu frontal) e 0,09 $\mathrm{MPa}$ (pneu traseiro), equipado com rodados de seis pneus e garra com capacidade de $1,95 \mathrm{~m}^{2}$.

\section{3 Áreas de estudo}

O experimento foi conduzido na zona de processamento, em faixas próximas ao carreador, em talhões com a mesma classificação de solo (PVA). As condições estudadas foram definidas como:

Condição A: área com plantio de eucalipto de 1,4 ano de idade (54,34 ha);

Condição B: área recém-colhida de eucalipto (12,53 ha);

Condição C: área com plantio de eucalipto de 6,0 anos de idade (12,42 ha).

Foram demarcadas 5 parcelas por talhão (condições) de $16 \mathrm{~m}$ de comprimento, no sentido do eito, por $10 \mathrm{~m}$ de largura, compreendendo 3 linhas de árvores e 27 árvores de eucalipto por parcela. A localização das parcelas em relação ao carreador, foi a uma distância de aproximadamente $5 \mathrm{~m}$.

\subsection{Variáveis analisadas}

\subsubsection{Compactação do solo}

Inicialmente, amostras de solo foram coletadas na profundidade de 0-40 cm com auxílio de uma sonda, para o cálculo do teor de água do solo durante a etapa de coleta de dados, determinado por meio do método gravimétrico, obtido pela relação entre a massa de água e a massa seca do solo em estufa, a $105^{\circ} \mathrm{C}$, por 24 horas.

Para a análise de densidade do solo, foram coletadas amostras indeformadas, utilizando-se o método do anel volumétrico (Ulland), em duas diferentes camadas do perfil do solo $(5-10 \mathrm{~cm}$ e $15-20 \mathrm{~cm})$ em 5 pontos aleatórios distribuídos entre as linhas de plantio. Após a coleta, as amostras foram colocadas em estufa, onde permaneceram durante 24 horas, sob temperatura de $105^{\circ} \mathrm{C}$. A densidade do solo foi calculada utilizando-se a seguinte expressão:

$\mathrm{Ds}=\mathrm{Ms} / \mathrm{V}$, onde:

Ds $=$ densidade do solo aparente $\left(\mathrm{Mg} \mathrm{m}^{-3}\right)$;

$\mathrm{Ms}=$ massa do solo seco em estufa a $105^{\circ} \mathrm{C}(\mathrm{Mg})$; $\mathrm{V}=$ volume amostra $\left(\mathrm{m}^{3}\right)$.

Um penetrômetro de impacto foi usado para medir a resistência do solo à penetração até a profundidade de $50 \mathrm{~cm}$. Todas as leituras, levando-se em consideração as

Cerne, Lavras, v. 20, n. 2, p. 191-198, abr./jun. 2014 
áreas de tratamento, foram feitas em um período bastante próximo, buscando-se evitar alterações no teor de água do solo. Foram realizadas 10 leituras de cada parcela por condição (total de 5 parcelas por condição) espaçadas aleatoriamente entre linhas e o número de impactos do penetrômetro foi transformado em $\mathrm{kPa}$, por meio da fórmula desenvolvida por Stolf (1991):

$\mathrm{RP}=560+689 \mathrm{~N}$, onde:

$\mathrm{RP}=$ resistência do solo à penetração em $\mathrm{kPa}$;

$\mathrm{N}=$ número de impactos por decímetro.

\subsubsection{Concentração de resíduos florestais}

A avaliação do impacto da concentração de resíduos considerou a determinação da sua quantidade, incluindo os restos da colheita florestal e também da serrapilheira (folhas, frutos e galhos senescentes), e os valores de fertilidade do solo.

Foram avaliadas as características de fertilidade do solo, por meio da análise química, em 10 amostras deformadas por parcela, coletadas na profundidade de $0-20 \mathrm{~cm}$ por meio de uma sonda. As 10 amostras coletadas por parcela foram misturadas e transformadas numa amostra de solo composta, totalizando uma amostra por parcela. O material foi posteriormente levado para o Laboratório de Ecologia Aplicada - LEA na ESALQ/USP, onde foram realizadas as análises de solo $\left(\mathrm{pH} \mathrm{em} \mathrm{CaCl}_{2}\right.$, Matéria Orgânica, Fósforo, Potássio, Cálcio, Magnésio, $\mathrm{H}+\mathrm{Al}$, os cálculos Soma de Bases, Capacidade de Troca Catiônica, Saturação de Base, Alumínio e cálculo de Saturação de Alumínio).

Para a amostragem dos resíduos, coletados aleatoriamente em 5 pontos por parcela, foi utilizado um anel de serrapilheira de alumínio perfurado, de 30 $\mathrm{cm}$ de diâmetro e $6 \mathrm{~cm}$ de altura. Os materiais coletados foram levados para estufa de ventilação forçada de ar a $65^{\circ} \mathrm{C}$, até atingirem peso constante. Foi determinada a quantidade de resíduos por tratamento, através do cálculo do valor médio de matéria seca.

\subsection{Análises estatísticas}

O delineamento experimental adotado foi o inteiramente casualizado, variando o número de repetições de acordo com as variáveis analisadas, por meio da análise de variância (ANOVA) e aplicação do teste F. O teste de médias utilizado foi o de Tukey, com $5 \%$ de significância.

\section{RESULTADOS E DISCUSSÃO}

A área com eucalipto recém-cortado (condição B) apresentou, significativamente, maior teor de água $(19,91 \%)$ em relação às outras condições $(13,76 \%$ e 15,77\% para as áreas com 1,4 e 6 anos de idade, respectivamente). Esse maior teor de água pode estar associado ao período de chuva durante a coleta dessas amostras e à presença, na superfície do solo, de grandes quantidades de resíduos provenientes da colheita florestal, que contribuíram para conservar a umidade (Tabela 1).

Tabela 1 - Teor de água do solo para os três condições na profundidade de $0-40 \mathrm{~cm}$.

Table 1 - Soil water content for the three conditions at a depth of $0-40 \mathrm{~cm}$.

\begin{tabular}{lcc}
\hline \multicolumn{1}{c}{ Condição } & \multicolumn{2}{c}{ Teor de água (\%) } \\
& U média & C.V. (\%) \\
\hline (A) Área com eucalipto de 1,4 ano de idade & 13,76 b & 12,75 \\
(B) Área recém colhida & 19,91 a & 12,95 \\
(C) Área com eucalipto de 6 anos de idade & 15,77 b & 13,36 \\
\hline \multicolumn{3}{c}{$\mathrm{F}=22,45^{*}$}
\end{tabular}

$\overline{\mathrm{U}}=$ teor de água. Média de 10 repetições por parcela (50 amostras por condição); C.V. = coeficiente de variação. Médias seguidas da mesma letra não diferem estatisticamente entre si, ao nível de $5 \%$ de probabilidade (teste de Tukey). *significativo ao nível de $5 \%$ de probabilidade (Teste F).

Os resultados indicaram uma maior quantidade significativa de resíduos florestais na área recém-colhida (condição B) $\left(28,44 \mathrm{t} \mathrm{ha}^{-1}\right)$ (Tabela 2), quando comparada aos obtidos na área com eucalipto de 1,4 ano $\left(10,62 \mathrm{tha}^{-1}\right) \mathrm{e}$ na área com eucalipto de 6 anos $\left(14,14 \mathrm{tha}^{-1}\right)$. A quantidade gerada de resíduos foi maior na área recém-colhida, em decorrência do depósito dos mesmos em faixas de solo próximas ao carreador, onde as amostras foram coletadas, que correspondem ao local onde o "Skidder" armazena as árvores. Souza et al. (2003) quantificaram a biomassa presente acima do solo em povoamentos de diferentes idades de Pinus taeda, no município de Três Barras - SC, verificando que houve um incremento da massa desse material com a idade dos indivíduos e que, após o décimo sétimo ano, o processo de deposição de material continuava sobrepondo-se ao da decomposição da serrapilheira. Os plantios de 17 anos apresentavam, respectivamente, 19,20; 2,05 e $0,44 \mathrm{t} \mathrm{ha}^{-1}$ de serrapilheira nas classes $\leq 0,70$; de 7,10 a 2,50 e de 2,51 a $7,60 \mathrm{~cm}$ de diâmetro.

Cerne, Lavras, v. 20, n. 2, p. 191-198, abr./jun. 2014 
Cunha et al. (2005) determinaram a biomassa e o conteúdo de nutrientes da parte aérea (folha, galho, casca e lenho) e da serrapilheira depositada e acumulada em povoamentos de Eucalyptus grandis em primeira rotação ( 8 anos de idade) e em sistema de rebrota (1,5 e 5 anos) na região Norte Fluminense. Segundo os mesmos, o talhão de 8 anos apresentou maior diâmetro, área basal e volume de tronco, portanto, a biomassa e o conteúdo de nutrientes nesse componente foram superiores aos de outros talhões. A produção total de serrapilheira e o fluxo anual de nutrientes no sistema planta-solo foram maiores no talhão em primeira rotação. $\mathrm{O}$ folhedo representou a maior contribuição para a deposição de nutrientes ao solo, e o balanço de nutrientes foi positivo em todos os talhões avaliados. Entretanto, houve baixa produção de biomassa, especialmente no talhão em primeira rotação, apesar de as reservas de nutrientes do solo permitirem maior produtividade.

Tabela 2 - Peso seco dos resíduos florestais em cada condição e estimativa da quantidade média de resíduos gerados por unidade de área $\left(\mathrm{t} \mathrm{ha}^{-1}\right)$.

Table 2 - Dry weight of forest residues in each condition and estimation of the average amount of residues generated per area $\left(t h a^{-1}\right)$.

\begin{tabular}{|c|c|c|c|}
\hline \multirow[t]{2}{*}{ Condição } & \multicolumn{2}{|c|}{$\begin{array}{l}\text { Peso dos resíduos } \\
\text { (g) }\end{array}$} & \multirow{2}{*}{$\begin{array}{l}\text { Peso dos resíduos } \\
\left(\mathrm{t} \mathrm{ha}^{-1}\right)\end{array}$} \\
\hline & Média & C.V. & \\
\hline $\begin{array}{l}\text { (A) Área com eucalipto de } \\
1,4 \text { ano de idade }\end{array}$ & $75,08 \mathrm{~b}$ & 64,37 & 10,62 \\
\hline (B) Área recém colhida & $201,05 \mathrm{a}$ & 64,50 & 28,44 \\
\hline $\begin{array}{l}\text { (C) Área com eucalipto de } 6 \\
\text { anos de idade }\end{array}$ & $99,98 \mathrm{~b}$ & 24,66 & 14,14 \\
\hline & $\mathrm{F}=13,69^{\circ}$ & & \\
\hline
\end{tabular}

Média de 5 repetições por parcela totalizando 25 amostras por condição; C.V. = coeficiente de variação (\%). ${ }^{\star}$ significativo ao nível de $5 \%$ de probabilidade (Teste F).

Os valores de densidade do solo, para as três condições, não diferiram significativamente entre si, demonstrando não haver, neste caso, influência do tráfego das máquinas com o passar dos anos na densidade do solo (Tabela 3).

Os valores médios de densidade do solo encontrados em todas as condições foram menores que o valor considerado crítico ao desenvolvimento das plantas, que é de $1,55 \mathrm{Mg}$ $\mathrm{m}^{-3}$ para os solos de textura média $(<20$ a $55 \%$ de argila) (REICHERT et al., 2003).

Cerne, Lavras, v. 20, n. 2, p. 191-198, abr./jun. 2014
Tabela 3 - Densidade do solo para as três condições em profundidades de até $20 \mathrm{~cm}$.

Table 3 - Bulk density for the three condições at depths of up to $20 \mathrm{~cm}$.

\begin{tabular}{|c|c|c|c|c|}
\hline \multirow{3}{*}{ Condição } & \multicolumn{4}{|c|}{ Profundidade $(\mathrm{cm})$} \\
\hline & \multicolumn{2}{|l|}{$5-10$} & \multicolumn{2}{|l|}{$15-20$} \\
\hline & $\begin{array}{l}\text { Densidade do } \\
\text { solo }\left(\mathrm{Mg} \mathrm{m}^{-3}\right)\end{array}$ & $\begin{array}{l}\text { C.V. } \\
(\%)\end{array}$ & $\begin{array}{l}\text { Densidade do } \\
\text { solo }\left(\mathrm{Mg} \mathrm{m}^{-3}\right)\end{array}$ & $\begin{array}{l}\text { C.V. } \\
(\%)\end{array}$ \\
\hline $\begin{array}{l}\text { (A) Eucalipto de 1,4 } \\
\text { ano de idade }\end{array}$ & $1,49 a^{*}$ & 5,92 & $1,48 \mathrm{a}$ & 6,93 \\
\hline $\begin{array}{l}\text { (B) Área recém } \\
\text { colhida }\end{array}$ & $1,45 \mathrm{a}$ & 10,25 & $1,48 \mathrm{a}$ & 10,46 \\
\hline \multirow[t]{2}{*}{$\begin{array}{l}\text { (C) Eucalipto de } 6 \\
\text { anos de idade }\end{array}$} & $1,44 \mathrm{a}$ & 3,68 & $1,47 \mathrm{a}$ & 3,23 \\
\hline & $\mathrm{F}=2,98^{\mathrm{ns}}$ & & $\mathrm{F}=0,04^{\mathrm{ns}}$ & \\
\hline
\end{tabular}

${ }^{\star}$ Média de 5 repetições por parcela e por profundidade (25 amostras por condição); C.V. = coeficiente de variação (\%). Médias seguidas da mesma letra não diferem estatisticamente entre si, a $5 \%$ de probabilidade (teste de Tukey). ns = não significativo.

Analisando os valores médios de RP nas cinco camadas estudadas (Tabela 4), observou-se que apenas na camada superficial do solo $(0-10 \mathrm{~cm})$ houve diferença significativa entre a área recém-colhida (condição $\mathrm{B}$ ) $(1,8 \mathrm{MPa})$ e as áreas com eucalipto de 1,4 e 6 anos $(1,2$ $\mathrm{MPa}$ ) indicando que, na área recém colhida, houve um incremento na compactação do solo causada pelo trânsito de equipamentos na colheita de madeira, mas que se reduz com o passar do tempo. É importante destacar que, de acordo com Tormena (2002), valores de RP entre 2 e 3 MPa são considerados limitantes para o desenvolvimento radicular, sendo que Dedecek e Gava (2005) consideram acima de 3 Mpa para o sistema radicular do eucalipto.

Analisando a RP em profundidade (Figura 1), verificou-se que os valores de RP foram sofrendo acréscimos ao longo do perfil do solo com o aumento da profundidade, a partir de $20 \mathrm{~cm}$ para todas as condições, atingindo os valores médios máximos na camada de 30 a $40 \mathrm{~cm}$. Em relação à profundidade, as atividades de fatores pedogenéticos resultantes da evolução do solo podem causar o adensamento de camadas subsuperficiais. Os materiais mais finos são transportados da superfície do solo e preenchem os vazios (poros) das camadas inferiores, aumentando sua resistência à penetração (CAMARGO; ALLEONI, 2010). 
Tabela 4 - Resistência à penetração do solo para as três condições até a profundidade de até $50 \mathrm{~cm}$.

Table 4 - Soil penetration resistance of the three conditions up to $50 \mathrm{~cm}$ depth.

\begin{tabular}{|c|c|c|c|c|c|c|c|c|c|c|}
\hline \multirow{4}{*}{ Condiç: } & \multicolumn{10}{|c|}{ Camadas $(\mathrm{cm})$} \\
\hline & \multicolumn{2}{|c|}{$0-10$} & \multicolumn{2}{|c|}{$10-20$} & \multicolumn{2}{|c|}{$20-30$} & \multicolumn{2}{|c|}{$30-40$} & \multicolumn{2}{|c|}{$40-50$} \\
\hline & \multicolumn{10}{|c|}{ Resistência à penetração (MPa) } \\
\hline & $\mathrm{RP}$ & C.V. & $\mathrm{RP}$ & C.V. & $\mathrm{RP}$ & C.V. & $\mathrm{RP}$ & C.V. & $\mathrm{RP}$ & C. \\
\hline $\begin{array}{c}\mathrm{A} \\
(\mathrm{U}=13,76 \%)\end{array}$ & $1,2 \mathrm{~b}$ & 20,3 & $2,0 \mathrm{a}$ & 38,1 & $3,2 \mathrm{a}$ & 36,1 & $3,3 \mathrm{a}$ & 39,1 & $2,3 \mathrm{a}$ & 27 \\
\hline $\begin{array}{c}\mathrm{B} \\
(\mathrm{U}=19,91 \%)\end{array}$ & $1,8 \mathrm{a}$ & 15,2 & $2,4 \mathrm{a}$ & 17,6 & $2,6 \mathrm{a}$ & 7,3 & $2,9 \mathrm{a}$ & 16,8 & $2,7 \mathrm{a}$ & 12 \\
\hline $\begin{array}{c}C \\
(\mathrm{U}=15,77 \%)\end{array}$ & $1,2 \mathrm{~b}$ & 6,5 & $2,3 \mathrm{a}$ & 46,2 & $3,5 \mathrm{a}$ & 26,6 & $3,6 \mathrm{a}$ & 29,0 & $2,5 \mathrm{a}$ & 26 \\
\hline & $\mathrm{F}=16$ & $6,45^{*}$ & $\mathrm{~F}=0$ & $0,64^{\text {ns }}$ & $\mathrm{F}=1$ & $56^{\mathrm{ns}}$ & $\mathrm{F}=0$ & $0,91^{\text {ns }}$ & $\mathrm{F}=0$ & 86 \\
\hline
\end{tabular}

$\mathrm{RP}=$ média de 10 repetições por parcela totalizando 50 leituras por tratamento; C.V. = coeficiente de variação (\%); $\mathrm{A}=$ área com eucalipto com 1,4 ano de idade; $\mathrm{B}$ = área recém colhida de eucalipto; $\mathrm{C}=$ área com eucalipto com 6,0 anos de idade; $\mathrm{U}=$ teor de água. Médias seguidas da mesma letra não diferem estatisticamente entre si, ao nível de $5 \%$ de probabilidade (teste de Tukey). * significativo ao nível de $5 \%$ de probabilidade (Teste F); ns = não significativo.

\section{Índice de Cone (MPa)}

$\begin{array}{lllllllll}0,0 & 0,5 & 1,0 & 1,5 & 2,0 & 2,5 & 3,0 & 3,5 & 4,0\end{array}$

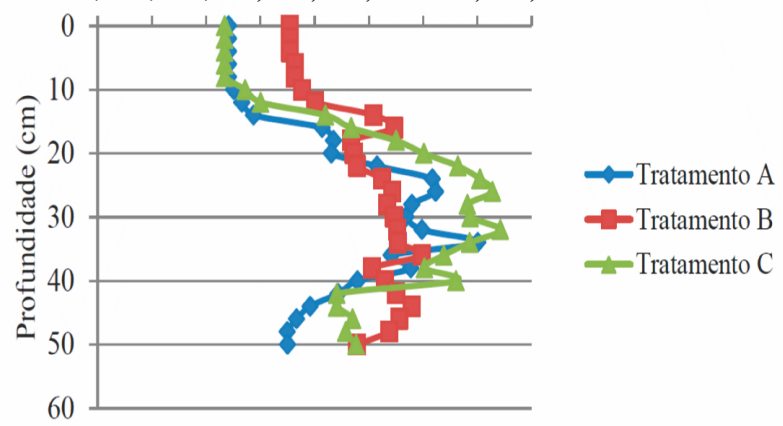

Figura 1 - Resistência do solo à penetração em profundidade para as condições estudadas.

Figure 1 - Distribution of soil penetration resistance in depth according to the studied condition.

Os resultados indicaram que os teores médios de fósforo $(\mathrm{P})$, potássio $(\mathrm{K})$, cálcio $(\mathrm{Ca})$ e capacidade de troca catiônica $(\mathrm{T})$, foram os que apresentaram diferenças estatisticamente significantes entre os tratamentos estudados (Tabela 5).
O teor médio de $\mathrm{P}$ no solo apresentou, significativamente, nível alto $\left(\geq 7 \mathrm{mg} \cdot \mathrm{dm}^{-3}\right)$ para a área com eucalipto de 1,4 ano (condição A) $\left(16,4 \mathrm{mg} \mathrm{dm}^{-3}\right)$, quando comparado aos teores médios $\left(>3 \mathrm{mg} \cdot \mathrm{dm}^{-3} \mathrm{e}<\right.$ $\left.7 \mathrm{mg} . \mathrm{dm}^{-3}\right)$ encontrados para a área recém-colhida $(4,0$ $\left.\mathrm{mg} . \mathrm{dm}^{-3}\right)$ e a área com eucalipto de 6 anos $\left(5,7 \mathrm{mg} \cdot \mathrm{dm}^{-3}\right)$, evidenciando a maior disponibilidade desse nutriente no solo, após a degradação da matéria orgânica concentrada próxima ao carreador.

Quanto ao teor médio de K, observou-se significância no baixo valor encontrado para a área com eucalipto de 6 anos (condição C) $\left(1,0 \mathrm{mmol}_{\mathrm{c}} \mathrm{dm}^{-3}\right)$, quando comparado aos valores médios $\left(1,6-3,0 \mathrm{mmol}_{\mathrm{c}} \mathrm{dm}^{-3}\right)$ (RAIJ et al., 1997) observados para a área com eucalipto de 1,4 ano (1,6 mmolc $\left.\mathrm{dm}^{-3}\right)$ e a área recém-colhida $\left(1,9 \mathrm{mmol}_{\mathrm{c}} \mathrm{dm}^{-3}\right), \mathrm{o}$ que pode estar relacionado com a mobilidade do elemento, tornando-o sujeito a lixiviação ou reabsorção rápida.

$\mathrm{O}$ teor de Ca médio observado foi estatisticamente significativo para a área com eucalipto de 6 anos (condição C), cujo valor foi superior (e bem acima do valor crítico) em relação às demais áreas de estudo, que também apresentaram valores acima dos teores adequados de $\mathrm{Ca}\left(10-20 \mathrm{mmol} / \mathrm{dm}^{3}\right)$ (GONÇALVES; POGGIANI, 1996). Maiores teores de $\mathrm{Ca}\left(103,0 \mathrm{mmol} / \mathrm{dm}^{3}\right)$ e de $\mathrm{Mg}$ (embora não significativo), encontrados para a área com eucalipto de 6 anos podem ser decorrentes, possivelmente, da decomposição dos resíduos florestais. Isso, porque, nesse povoamento, não se fez a aplicação de fertilizantes ou corretivos cuja fonte contivesse $\mathrm{Ca}$ e $\mathrm{Mg}$ na sua composição na rotação atual, além do fato desses elementos serem exigidos em menores quantidades pelo eucalipto nessa idade (CAVICHIOLLO et al., 2004).

Com relação a $T$, o maior valor significativo encontrado, comparando-se as três condições, foi a área com eucalipto de 6 anos (condição C). Os maiores teores de $\mathrm{Ca}, \mathrm{Mg}$ e de $\mathrm{T}$ presentes na área com eucalipto de 6 anos, ressaltam a contribuição da matéria orgânica para a capacidade de troca desses solos.

Conclui-se que, pelos teores médios dos macroelementos, os solos das áreas de estudo com eucalipto de 1,4 (condição A) e 6 anos (condição C) apresentaram boas condições de fertilidade, destacando-se a área com eucalipto de 6 anos.

\section{CONCLUSÕES}

A compactação causada pelo tráfego das máquinas de colheita não atingiu níveis considerados críticos para

Cerne, Lavras, v. 20, n. 2, p. 191-198, abr./jun. 2014 
Tabela 5 - Análise da fertilidade do solo $(0-20 \mathrm{~cm})$ para as três condições estudadas.

Table 5 - Analysis of soil fertility $(0-20 \mathrm{~cm})$ for the three studied conditions.

\begin{tabular}{cccccccccc}
\hline Condição & $\begin{array}{c}\mathrm{pH}^{1} \\
\left(\mathrm{CaCl}_{2}\right)\end{array}$ & $\begin{array}{c}\text { M.O. } \\
\left(\mathrm{g} \mathrm{dm}^{-3}\right)\end{array}$ & $\begin{array}{c}\mathrm{P} \\
\left(\mathrm{mg} \mathrm{dm}^{-3}\right)\end{array}$ & $\mathrm{K}$ & $\mathrm{Ca}$ & $\mathrm{Mg}$ & $\mathrm{Al}$ & $\mathrm{T}$ & $\begin{array}{c}\mathrm{V} \\
(\%)\end{array}$ \\
\hline $\mathrm{A}$ & $5,7 \mathrm{a}$ & $18,0 \mathrm{a}$ & $16,4 \mathrm{a}$ & $1,6 \mathrm{a}$ & $36,4 \mathrm{~b}$ & $7,4 \mathrm{a}$ & $2,0 \mathrm{a}$ & $66,0 \mathrm{a}$ & $68,8 \mathrm{a}$ \\
$\mathrm{B}$ & $4,9 \mathrm{a}$ & $15,7 \mathrm{a}$ & $4,0 \mathrm{~b}$ & $1,9 \mathrm{a}$ & $21,0 \mathrm{~b}$ & $7,7 \mathrm{a}$ & $6,3 \mathrm{a}$ & $65,0 \mathrm{a}$ & $46,3 \mathrm{a}$ \\
$\mathrm{C}$ & $5,8 \mathrm{a}$ & $19,3 \mathrm{a}$ & $5,7 \mathrm{~b}$ & $1,0 \mathrm{~b}$ & $103,0 \mathrm{a}$ & $11,0 \mathrm{a}$ & $12,7 \mathrm{a}$ & $142,3 \mathrm{~b}$ & $69,7 \mathrm{a}$ \\
\cline { 2 - 10 } & $2,7^{\text {ns }}$ & $1,7^{\text {ns }}$ & $12,0^{* *}$ & $9,3^{* *}$ & $7,6^{* *}$ & $2,0^{\text {ns }}$ & 2,0 & $13,0^{* *}$ & $2,8^{\text {ns }}$
\end{tabular}

${ }^{1}$ Média de 5 amostras de solo compostas por condição (1 amostra de solo composta por parcela num total de 5 parcelas/condição); C = Condição; $\mathrm{A}=$ área com eucalipto de 1,4 ano de idade; $\mathrm{B}=$ área recém colhida de eucalipto; $\mathrm{C}=$ área com eucalipto de 6,0 anos de idade; U = teor de água. Extratores: M.O.: Oxi-Red.; pH: Sol. $\mathrm{CaCl}_{2} ; \mathrm{S}_{-} \mathrm{SO}_{4}{ }^{2-}: \mathrm{BaCl}_{2}$ em pó; P, K, Ca, Mg: Resina; $\mathrm{Al}$ : KCl; T (Capacidade de Troca Catiônica); V (Saturação de Bases): Cálculo. ${ }^{*}$ Significativo ao nível de $5 \%$ de probabilidade (Teste F); ns = não significativo.

o desenvolvimento do sistema radicular do eucalipto. Foi constatada diminuição da compactação do solo com o passar do tempo, quando considerado a RP, mas tal fato não foi confirmado pelos valores de densidade do solo. A presença de resíduos da colheita é fator positivo quanto à maior concentração de nutrientes no solo, no decorrer do processo de degradação e incorporação da matéria orgânica, mas a sua localização próxima ao carreador deve ser minimizada, recomendando-se a sua distribuição por todo o talhão.

\section{REFERÊNCIAS}

CAMARGO, O. A.; ALLEONI, L. R. Causas da compactação do solo. Disponível em: <http://www. infobibos.com/Artigos/CompSolo/C3/Comp3.htm>. Acesso em: 11 jul. 2010.

CAVICHIOLLO, S. R.; DEDECEK, R. A.; GAVA, J. L. Preparo do solo e o estado nutricional da rebrota de Eucalyptus saligna. Scientia Forestalis, Piracicaba, n. 66, p. 120-127, dez. 2004.

CUNHA, G. M.; GAMA-RODRIGUES, A. C. da; COSTA, G. S. Ciclagem de nutrientes em Eucalyptus grandis W. Hill ex Maiden no Norte Fluminense. Revista Árvore, Viçosa, v. 29, n. 3, p. 353-363, maio/jun. 2005.

CZYZ, E. A. Effects of traffic on soil aeration, bulk density and growth of spring barley. Soil and Tillage Research, Amsterdam, v. 79, p. 153-166, Dec. 2004.

DEDECEK, R. A.; GAVA, J. L. Influência da compactação do solo na produtividade da rebrota de eucalipto. Revista Árvore, Viçosa, v. 29, n. 3, p. 383-390, maio/jun. 2005.

DIAS JUNIOR, M. S. Compactação do solo. In: NOVAIS, R. F.; ALVAREZ, V. V. H.; SCHAEFER, C. E. G. R. (Ed.). Tópicos em ciência do solo. Viçosa, MG: Sociedade Brasileira de Ciência do Solo, 2000. v. 1, p. 55-94.

DIAS JUNIOR, M. S.; LEITE, F. P.; LASMAR JÚNIOR, E.; ARAÚJO JUNIOR, C. F. Traffic effects on the soil preconsolidation pressure due to eucalyptus harvest operations. Scientia Agricola, Piracicaba, v. 62, n. 3, p. 248-255, May/June 2005.

FENNER, P. T. Compactação do solo. In: MACHADO, C. C. (Ed.). Colheita florestal. Viçosa, MG: UFV, 2002. p. $375-396$.

GONÇALVES, J. L. M.; POGGIANI, F. Substratos para produção de mudas florestais. In: CONGRESSO LATINO AMERICANO DE CIÊNCIA DO SOLO, 13., 1996, Águas de Lindóia. Resumos... Águas de Lindóia: Sociedade Brasileira de Ciência do Solo, 1996. 1 CDROM.

GONÇALVES, J. L. M.; POGGIANI, F.; STAPE, J. L.; SERRANO, M. I. P.; MELLO, S. L. M.; MENDES, K. C. F. S.; JORGE, L. A. C. Efeito de práticas de cultivo mínimo e intensivo do solo sobre a ciclagem de nutrientes, fertilidade do solo, configuração do sistema radicular e nutrição mineral de povoamentos de Eucalyptus grandis. Piracicaba: FAPESP, 1997. 94 p. Relatório final de pesquisa, FAPESP, processo $\mathrm{n}^{\circ}$ 1994/4248-4.

Cerne, Lavras, v. 20, n. 2, p. 191-198, abr./jun. 2014 
GRANT, C. A.; LAFOND, G. P. The effects of tillage systems and crop sequences on soil bulk density and penetration resistence on a clay soil in Southern Saskatchewan. Canadian Journal of Soil Science, Ottawa, v. 73, n. 2, p. 223-232, May 1993.

ISHAQ, M.; HASSAN, A.; SAEED, M.; IBRAHIM, M.; LAL, R. Subsoil compaction effects on crops in Punjab, Pakistan: I., soil physical properties and crop yield. Soil and Tillage Research, Amsterdam, v. 59, p. 57-65, Apr. 2001.

LIMA, J. S. S.; SOUZA, A. P.; MACHADO, C. C.; OLIVEIRA, P. C.; MARTINS FILHO, S. Estudo do comportamento da resistência do solo à penetração em trilha de tráfego na colheita de madeira. In: SIMPÓSIO BRASILEIRO SOBRE COLHEITA E TRANSPORTE FLORESTAL, 2001, Porto Seguro. Anais... Viçosa, MG: SIF, 2001. v. 5, p. 281-289.

OUSSIBLE, M.; CROOKSTON, P. K.; LARSON, W. E. Subsurface compaction reduces the root and shoot growth and grain yield of wheat. Agronomy Journal, Madison, v. 84, n. 1, p. 34-38, 1992.

RAIJ, B. van; CANTARELLA, H.; QUAGGIO, J. A.; FURLANI, A. M. C. Recomendações de adubação e calagem para o Estado de São Paulo. 2. ed. Campinas: Instituto Agronômico; Fundação IAC, 1997. 297 p. (Boletim Técnico, 100).

REICHERT, J. M.; REINERT, D. J.; BRAIDA, J. A. Qualidade dos solos e sustentabilidade de sistemas agrícolas. Revista Ciência \& Ambiente, Santa Maria, v. 27, p. 29-48, jul./dez. 2003.

SOUZA, L. J. B. de; SOARES, R. V.; BATISTA, A. C. Modelagem de material combustível em plantações de Pinus taeda no norte de Santa Catarina. Revista Floresta, Curitiba, v. 33, n. 2, p. 157-168, 2003.

STOLF, R. Teoria e teste experimental de fórmulas de transformação dos dados de penetrômetro de impacto em resistência do solo. Revista Brasileira de Ciência do Solo, Campinas, v. 15, p. 229-235, 1991.

TORMENA, C. A. A compactação do solo em agroecossistemas agrícolas. In: REUNIÃO BRASILEIRA DE MANEJO E CONSERVAÇÃO DO SOLO E DA ÁGUA, 14., 2002, Viçosa, MG. Anais... Viçosa, MG: Sociedade Brasileira de Ciência do Solo, 2002. 1 CD-ROM.

Recebido: 25 de novembro de 2011; aceito: 23 de agosto de 2013. 
